\title{
First applications of a targeted exome sequencing approach in fetuses with ultrasound abnormalities reveals an important fraction of cases with associated gene defects
}

Constantinos Pangalos, Birgitta Hagnefelt, Konstantinos Lilakos, Christopher Konialis

Background. Fetal malformations and other structural abnormalities are relatively frequent findings in the course of routine prenatal ultrasonographic examination. Due to their considerable genetic and clinical heterogeneity, the underlying genetic cause is often elusive and the resulting inability to provide a precise diagnosis precludes proper reproductive and fetal risk assessment. We report the development and first applications of an expanded exome sequencing-based test, coupled to a bioinformatics-driven prioritization algorithm, targeting gene disorders presenting with abnormal prenatal ultrasound findings.

Methods. We applied the testing strategy to14 euploid fetuses, from 11 on-going pregnancies and 3 products of abortion, all with various abnormalities or malformations detected through prenatal ultrasound examination. Whole exome sequencing (WES) was followed by variant prioritization, utilizing a custom analysis pipeline (Fetalis algorithm), targeting 758 genes associated with genetic disorders which may present with abnormal fetal ultrasound findings.

Results. A definitive or highly-likely diagnosis was made in 6 of 14 cases (43\%), of which 3 were abortuses (Ellis-van Creveld syndrome, Ehlers-Danlos syndrome and Nemaline myopathy 2) and 3 involved on-going pregnancies (Citrullinemia, Noonan syndrome, PROKR2-related Kallmann syndrome). In the remaining 8 on-going pregnancy cases (57\%), a ZIC1 variant of unknown clinical significance was detected in one case, while in 7 cases testing did not reveal any pathogenic variant(s). Pregnancies were followed-up to birth, resulting in one neonate harboring the PROKR2 mutation, presenting with isolated minor structural cardiac abnormalities, and in 7 apparently healthy neonates.

Discussion. The expanded targeted exome sequencing-based approach described herein (Fetalis), provides strong evidence suggesting a definite and beneficial increase in our diagnostic capabilities in prenatal diagnosis of otherwise chromosomally balanced fetuses with troubling ultrasound abnormalities. Furthermore, the proposed targeted exome sequencing strategy, designed primarily as a diagnostic rather than a research discovery tool, overcomes many of the problems and limitations associated with clinical wide-scale WES testing in a prenatal setting. 
1 TITLE: First applications of a targeted exome sequencing approach in fetuses with

2 ultrasound abnormalities reveals an important fraction of cases with associated gene

3 defects

4

5 Constantinos Pangalos ${ }^{1,2} \S$, Birgitta Hagnefelt ${ }^{2}$, Konstantinos Lilakos ${ }^{3}$, Christopher Konialis, ${ }^{1,2}$

6

$7{ }^{1}$ Genomis Ltd, Lynton House, 7-12 Tavistock Square, London WC1H 9BQ, U.K.

$8 \quad{ }^{2}$ InterGenetics - Diagnostic Genetic Centre, 120 Vas. Sofias Ave., Athens 11526, Greece

$9{ }^{3}$ Department of Haematology, "Laikon" General Hospital, University of Athens Medical School,

10 Athens, Greece

11

12

13

19 §CORRESPONDING AUTHOR:

20 Prof. Constantinos Pangalos

21 InterGenetics - Diagnostic Genetic Centre

22120 Vas.Sofias Ave., Athens 11526, Greece.

23 Tel.: + 2107705010, Fax: +210 7705011

24 E-mail: info@intergenetics.eu 
ABSTRACT

Background. Fetal malformations and other structural abnormalities are relatively frequent

findings in the course of routine prenatal ultrasonographic examination. Due to their

considerable genetic and clinical heterogeneity, the underlying genetic cause is often elusive and the resulting inability to provide a precise diagnosis precludes proper reproductive and fetal risk assessment. We report the development and first applications of an expanded exome sequencingbased test, coupled to a bioinformatics-driven prioritization algorithm, targeting gene disorders presenting with abnormal prenatal ultrasound findings.

Methods. We applied the testing strategy to14 euploid fetuses, from 11 on-going pregnancies and 3 products of abortion, all with various abnormalities or malformations detected through prenatal ultrasound examination. Whole exome sequencing (WES) was followed by variant prioritization, utilizing a custom analysis pipeline (Fetalis algorithm), targeting 758 genes associated with genetic disorders which may present with abnormal fetal ultrasound findings. Results. A definitive or highly-likely diagnosis was made in 6 of 14 cases (43\%), of which 3 were abortuses (Ellis-van Creveld syndrome, Ehlers-Danlos syndrome and Nemaline myopathy 2) and 3 involved on-going pregnancies (Citrullinemia, Noonan syndrome, PROKR2-related Kallmann syndrome). In the remaining 8 on-going pregnancy cases (57\%), a ZIC1 variant of unknown clinical significance was detected in one case, while in 7 cases testing did not reveal any pathogenic variant(s). Pregnancies were followed-up to birth, resulting in one neonate harboring the $P R O K R 2$ mutation, presenting with isolated minor structural cardiac abnormalities, 47 and in 7 apparently healthy neonates. 
48 Discussion. The expanded targeted exome sequencing-based approach described herein

49 (Fetalis), provides strong evidence suggesting a definite and beneficial increase in our diagnostic

50 capabilities in prenatal diagnosis of otherwise chromosomally balanced fetuses with troubling

51 ultrasound abnormalities. Furthermore, the proposed targeted exome sequencing strategy,

52 designed primarily as a diagnostic rather than a research discovery tool, overcomes many of the

53 problems and limitations associated with clinical wide-scale WES testing in a prenatal setting. 


\section{INTRODUCTION}

77 Recognizable fetal ultrasound (US) abnormalities are observed in approximately 3-5\% of all pregnancies, while congenital abnormalities account for $20-25 \%$ of perinatal deaths (Centers for Disease Control and Prevention (CDC) 2008; Romosan et al., 2009). In everyday clinical practice, prenatal detection and prevention of severe congenital disorders is typically achieved through various levels of fetal ultrasonographic examination in the $1^{\text {st }}$ or $2^{\text {nd }}$ trimester of pregnancy; however, precise diagnosis of the underlying genetic defect is often challenging and elusive due to considerable clinical and genetic heterogeneity (Rice et al., 2011; Ermito al., 2009; Schramm et al., 2009), while an exasperating factor is the lack in most cases of prior family history or other identifiable predisposing risks (Long \& Sprigg, 1998).

86 In these cases, advances in molecular genetics nowadays offer a more detailed prenatal genetic

87 investigation, mainly for chromosomal abnormalities revealed through array comparative 88 genomic hybridization (aCGH), although the diagnostic yield from these studies typically does not exceed $\sim 10-15 \%$ (Konialis \& Pangalos, 2015; Hillman et al., 2013), leaving a considerable residual risk for a potentially debilitating genetic disorder. Furthermore, genetic testing for gene mutations associated with the observed ultrasound abnormalities is limited to targeted testing of

92 very few distinct genes suspected to be involved in the particular case and therefore 
93 comprehensive testing for gene disorders in the course of pregnancy has been highly selective

94 and thus largely ineffective (Milunsky \& Milunsky, 2015).

As an example, skeletal malformations and dysplasias, often detected through routine prenatal

96 ultrasound examination, constitute a phenotypic finding in more than 300 syndromic and non-

97 syndromic disorders and their genetic etiology may be due to a wide variety of genetic

98 aberrations, ranging from copy number variations to single gene mutations. Similarly, fetal limb

99 deformities, such as structural abnormalities of the fingers and toes (clinodactyly, polydactyly, etc.), are relatively frequent ultrasonographic findings and are also associated with a variety of syndromic and non-syndromic genetic disorders (Warman et al., 2011; Porter \& Herman, 2011). The above may be expressed as dominant, recessive, or X-linked disorders or they may be the result of spontaneous de novo mutations, while many forms present with variable phenotypic expression and are more difficult to diagnose compared to lethal forms. Therefore, it is more than evident that fetal structural malformations and other fetal abnormalities revealed through prenatal ultrasound are characterized by considerable phenotypic and genetic heterogeneity. For example, single gene such as $D H C R 7$, may be associated with a variety of ultrasound findings, which may include skeletal malformations and/or genitourinary abnormalities (e.g. hypospadias), typically associated with Smith-Lemli-Opitz syndrome. Similarly, other genes involved together with $D H C R 7$ in the cholesterol biosynthesis pathway, are also associated with a number of

111 genetic disorders/syndromes (e.g. Antley-Bixler syndrome - POR gene), presenting with several

112 common prenatal clinical manifestations (Porter \& Herman, 2011).

113 As a rule, abnormal ultrasound findings require detailed genetic counseling, where the merits and

114 limitations of available genetic testing options are discussed as well as the associated risks.

115 However, an accurate diagnosis is a highly desirable prerequisite in this process, not only for 
116 parental decisions regarding the outcome of the current pregnancy but also for providing

117 accurate counseling for the risk for future pregnancies and this is even more important in

118 families with recurrent fetal ultrasonographic findings, pointing to an underlying inherited

119 genetic disease.

120 Very recently, a rather limited number of retrospective studies, utilizing whole genome

121 sequencing (Talkowski et al., 2012) or whole exome sequencing (WES) in small cohorts of

122 neonates and aborted fetuses with various ultrasound and/or post-mortem structural

123 abnormalities (Carss et al., 2014; Drury at al., 2015; Alamillo et al., 2015; Westerfield et al.,

124 2015), provided initial proof-of-principle of large-scale prenatal next generation sequencing

125 (NGS). The results from these studies have been the subject of a recent review and debate (Filges

126 \& Friedman, 2015; Chitty, Friedman \& Langlois, 2016), where both the merits and limitations of

127 WES applications in malformed fetuses are presented. In addition, it appears that the majority of

128 couples have a positive attitude towards prenatal WES testing, particularly when confronted with

129 troubling fetal ultrasound findings (Kalynchuk et al., 2015).

130 We present our initial findings and follow-up results, derived from a custom designed targeted 131 exome sequencing strategy, as applied prospectively (on-going pregnancy) and retrospectively

132 (abortuses) in a cohort of 14 euploid fetuses, all presenting with various ultrasonographic

133 anomalies. This approach may afford a timely diagnosis in the course of pregnancy, while

134 overcoming many of the pitfalls associated with large-scale prenatal NGS. We also discuss the

135 potential benefits, the challenges and future developments of this testing strategy, through our

136 central view of maintaining a careful and desirable balance between an increase in diagnostic

137 potential and the undesirable 'grey zones' in prenatal diagnosis. 
139 MATERIALS AND METHODS

140 Cases and samples

141 Prenatal cases included in this study (period 03/2015-9/2015, Table 1) were referred to our

142 center for diagnostic genetic testing from maternity hospitals or fetal medicine centers

143 throughout Greece and where the invasive procedure was performed. All cases involved euploid

144 fetuses ascertained by prior prenatal aCGH, performed as previously described (Konialis \&

145 Pangalos, 2015). The study is in compliance with the Helsinki Declaration and in all cases

146 mandatory pre-test genetic counseling was provided initially by the referring physician and

147 subsequently in-house, where all couples were counseled specifically on all aspects of the

148 genomic testing to be performed, particularly as applied in prenatal diagnosis, and provided their

149 informed consent.

150 The samples consisted of either amniotic fluid (AF) or chorionic villi sampling (CVS) and were

151 accompanied by our prenatal testing requisition form, stating the clinical indications (ultrasound

152 findings and/or abortus autopsy reports). Parental peripheral blood samples were also collected

153 for confirmatory analysis and/or follow-up testing.

154 Whole Exome Libraries

155 Genomic DNA was isolated using the QIAamp DNA Blood Mini Kit (Qiagen, Valencia, CA), 156 quantified by the Qubit 2.0 fluorometer (Life Technologies, Thermo Fisher Scientific, USA), 157 assessed on the Agilent TapeStation 2200 (Agilent Technologies Inc., USA) and 120 ng was 158 subsequently subjected to whole exome DNA library construction using the Ion AmpliSeq 159 Whole Exome RDY (Life Technologies, Thermo Fisher Scientific, USA) essentially as described 160 in the manufacturer's protocol, with barcode incorporation. 
161 AmpliSeq HiQ libraries for sequencing were prepared on the Ion OneTouch 2 system,

162 quantified using the Qubit 2.0 fluorometer (Life Technologies, Thermo Fisher Scientific, USA)

163 and massive parallel sequencing (MPS) was subsequently performed on the Ion Proton System

164 utilizing a PI chip (Life Technologies, Thermo Fisher Scientific, USA), with 2 or 3 samples (in

165 cases of family trio) loaded per run.

166 Data Analysis

167 Primary sequence data analysis was performed using Torrent Suite (4.2.0) with default 168 parameters and variant calling was performed using the Ion Torrent Variant Caller (TSVC) plug169 in (version 4.2-8-r87740) using default settings and relative to NCBI37/hg19 reference assembly.

170 The resulting variants (vcf file) were annotated through the Ion Reporter 4.4 or 5.0 variant 171 annotation analysis function and the annotated variants were subsequently imported for filtering, 172 prioritization and evaluation into a local Exome Management Application (EMA) custom 173 pipeline.

174

175 Gene selection and variant prioritization - Fetalis algorithm

176 We selected an extensive panel of 758 genes (Table S1) associated with genetic disorders, which

177 may present with fetal structural abnormalities detectable in the $1^{\text {st }}, 2^{\text {nd }}$ or $3^{\text {rd }}$ trimester by 178 ultrasound and/or other fetal monitoring techniques (e.g. echocardiogram, MRI, etc.). 179 Mitochondrial DNA genes are not included. The list of genes and disorders was carefully 180 compiled and manually curated using data from various sources (OMIM, Borrelli et al., 2008; 181 Stenson et al., 2009; Bell et al., 2011; Saunders et al., 2012; GeneTests, 2015; Milunsky \& 182 Milunsky, 2015; Sabbagha, Tamura \& Sabbagha, 2015; HPO database - Köhler et al., 2014), 183 including the HPO-driven built-in function of the EMA pipeline. The Fetalis 758 genes and 
184 variant prioritization algorithm (Konialis $\mathrm{C}$ and Agioutantis Z, unpublished data) was 185 specifically designed for hierarchical evaluation of gene variants, based on up to three user186 selectable main ultrasonographic clinical findings, utilizing imported Human Phenotype 187 Ontology (HPO) terminology (Köhler et al., 2014) and Phenomizer data (Köhler et al., 2009, $188 \mathrm{http}: / /$ compbio.charite.de/phenomizer/). In several instances, where HPO and/or Phenomizer 189 terms and gene associations were not available, these were constructed and incorporated into the 190 EMA-Fetalis pipeline database. The Fetalis pipeline is coupled to other built-in standard filtering 191 functions in the EMA pipeline, such as mutation pathogenicity score, variant population 192 frequency (1000GP, NHLBI Exome Variant Server - EVS, ExAC consortium, local Greek 193 variant database), etc.. Final interpretation of results was performed manually, on the basis of the 194 hierarchy ranking of the gene variants from the EMA-Fetalis algorithm, clinical experience and 195 generally in accordance with published guidelines (Richards et al., 2015). Specifically in cases 196 where clinical reports were made available in an on-going pregnancy, we decided to evaluate 197 and report variants as having clinical significance only when falling into the following two categories: (a) known pathogenic mutations, previously reported in the literature and/or in 199 mutation databases, and (b) 'obligatory pathogenic' variants, of the type nonsense, frameshift, indels, canonical splice-site variants ( \pm 2 intron donor-acceptor splice-sites). In selected cases 201 (see Results), other type of variants, not included in any of the above categories (e.g. AR 202 disorders - combination in a single gene of one known pathogenic mutation and one highly-likely pathogenic mutation), were also evaluated and reported (Richards et al., 2015). Standard Sanger DNA sequencing was used for variant confirmation and segregation analysis.

\section{RESULTS}


207 Prenatal cases were referred and considered for testing based on the type and severity of the

208 reported fetal ultrasound findings or other fetal abnormalities observed post-mortem.

209 Specifically for on-going pregnancies, during pre-test counseling and prior to providing their

210 informed consent, couples were informed that testing is targeted, that it will not reveal or report

211 incidental findings and that it will only evaluate and report variants/mutations included in the

212 aforementioned categories (see Materials and Methods).

213 In order to be able to provide a timely diagnosis in on-going pregnancies, we evaluated and

214 subsequently applied the use of the remaining DNA sample, extracted directly from uncultured

215 amniotic fluid or CVS samples, following previous prenatal aCGH testing. As the Ion Ampliseq

216 Exome RDY reagent typically requires no more than 100-130 ng of input DNA, this type of

217 library preparation coupled to MPS on the Ion Proton PI chip afforded a rapid protocol, not

218 necessitating cell culture and able to deliver interpretable results in less than 10 days, including

219 confirmatory analysis. All 14 fetal samples yielded whole exome libraries within acceptable

220 quality criteria. The technical analysis parameters from each sample are provided in Data S1. On

221 average, a total of approximately $2200 \pm 50$ variants per sample/case were detected corresponding

222 to the 758 genes ( $\sim 1030$ variants occurring in exons, 1-3 variants in splice sites); following gene

223 prioritization (based on the reported ultrasonographic abnormalities for each case) and variant

224 filtering through the Fetalis algorithm, approximately 1-3 potentially significant

225 variants/mutations were left for manual inspection and final clinical evaluation, with no

226 incidental findings. As an example, applying the Fetalis algorithm in Case 7 (see Table 1), a total

227 of 243 exonic and splice-site variants were identified in 134 genes (out of the 758 Fetalis genes),

228 prioritized due to their association with genetic disorders which may possibly include

229 abnormalities of the cerebellar vermis and/or with Dandy-Walker malformation. Further filtering 
230 and prioritization through the EMA-Fetalis built-in parameters for: (a) variant frequency against

231 our local Greek variant database, (b) for variant frequency against international databases

232 (1000GP, EVS, ExAc) and (c) for pathogenicity score and variant class, resulted in 2 potentially

233 significant missense variants/mutations requiring final manual curation and clinical evaluation

234 (c.1375C $>$ T - p.R459C in the CHD7 gene and the c.1208C $>$ A - p.S403Y in the ZIClgene). The

235 CHD7 gene missense mutation was quickly dismissed based on several factors (e.g. disease-

236 phenotype association and relatively common allele frequency in ExAc), while the maternally-

237 inherited ZIC1 missense variant was at the time reported as a VOUS (see note added in proof).

238 Even allowing for Sanger sequencing confirmation and segregation analysis, final results were

239 available in less than 10 days, with the potential of attaining an even faster turn-around time $(<5$

240 days).

241

242 The Fetalis targeted (758 genes) exome sequencing strategy provided overall a clinical diagnosis

243 in 5 of 14 cases (36\%, Table 1, cases $1-5)$, involving 3 products of abortion (Cohort 1 , cases 1-3)

244 and 2 on-going pregnancies (Cohort 2, cases 4 and 5). In one further on-going pregnancy case

245 (Table 1, case 6), a highly-likely diagnosis of PROKR2-related autosomal dominant Kallmann

246 syndrome was made, involving a known pathogenic mutation. Also, in another on-going

247 pregnancy (Table 1, case 7), a novel probably pathogenic missense variant/mutation was

248 detected in the ZICl gene, which was maternally inherited and was reported as a variant of

249 unknown clinical significance (VOUS). In the remaining 7 on-going-pregnancies (Table 1, cases

250 8-13), Fetalis testing did not reveal a known or 'obligatory' pathogenic mutation (see Materials

251 and Methods) in the fetus, possibly associated with the reported ultrasound abnormalities.

252 Cohort 1 - abortuses 
253 In Case 1, a 24 year old G2P0+1 female was referred for genetic counseling following

254 termination of pregnancy at 27 weeks of gestation. A prior US examination revealed a male fetus

255 with bilateral limb abnormalities (polydactyl, short hand, brachydactyly) and talipes

256 equinovarus. A histopathological examination of the abortus had not been performed. The results

257 revealed the presence of 2 heterozygous missense variants: c.2776G $>$ A (p.Glu926Lys) and

258 c.707T $>$ C (p.Val236Ala), in exon 7 and 17, respectively, of the EVC2 gene. The variants are not

259 present in dbSNP, 1000 GP, EVS Variant Server, while they are both present in the ExAc

260 database with allele frequencies of $1.647 \mathrm{e}-05$ and $2.48 \mathrm{e}-05$, respectively. The variant c.2776G $>$ A

261 was predicted as possibly damaging, while the c.707T $>\mathrm{C}$ variant, occurring at the first base of

262 exon 7, had a predicted non-pathogenic effect in terms of the amino-acid substitution (valine to

263 alanine); however, a variety of in silico tools predicted to affect proper splicing of exon 7

264 through disruption of the acceptor splice-site. Subsequent Sanger sequencing of the parents

265 determined that each was heterozygous for one of the variants, the c.707T $>\mathrm{C}$ variant originating

266 from the mother and the c.2776G $>$ A originating from the father, thus confirming compound

267 heterozygosity and autosomal recessive inheritance. Mutations in the EVC2 gene are known to

268 be the cause of autosomal recessive Ellis-van Creveld syndrome (EVC, OMIM 225500) and

269 autosomal dominant Weyers acrodental dysostosis (MIM 193530), rare malformation syndromes

270 with a number of common phenotypic features, which include limb malformations (e.g.

271 syndactyly, polydactyly) (Mankin HJ, Jupiter J \& Trahan CA, 2011; Shen W et al., 2011). Thus,

272 the two mutations of the EVC2 gene detected in this case, combined with the reported US

273 findings in the fetus provide an almost unequivocal diagnosis of EVC, and novel mutations with

274 variable expressivity are very often uncovered in newly investigated patients [D'Asdia MC et al., $2752013]$. 
276 Cases 2 and 3 (Table 1) also involved abortuses with several US abnormalities, which had

277 prompted the couples to terminate the pregnancy. In Case 2, with IUGR, joint contractures, mild

278 hydrocephalus and decreased fetal movements, the fetus was found to be compound

279 heterozygous for two missense variants/mutations of the $N E B$ gene: a novel c.11060C $>\mathrm{T}$

280 (p.Ala3687Val) variant/mutation not present in public databases and a c.11333T $>$ C

281 (p.Ile3778Thr) variant/mutation present in the ExAc database with an allele frequency of 9.113e-

28205 , both predicted as probably pathogenic. The parents were heterozygous-carriers for the

283 mutations (c.11060C $>$ T maternal, c.11333T $>$ C paternal), while testing of a remaining fetal DNA

284 sample from the previous similarly affected pregnancy confirmed the presence of both mutations

285 in that fetus as well. Mutations in the $N E B$ gene are associated with autosomal recessive

286 Nemaline myopathy 2 (OMIM 2560), a congenital form of which may present with US findings

287 during pregnancy, similar to those reported in this fetus (OMIM; Lammens M et al., 1997; Ryan

288 MM et al., 2001). In Case 3, a hypoplastic right antebrachium, wrist and phalangeal defects of

289 the right hand of the fetus were reported, with no other major post-mortem autopsy findings.

290 Testing revealed the heterozygous presence of a nonsense COL $3 A 1$ c.811C $>$ T (p.R271X)

291 mutation, associated with Ehlers-Danlos syndrome IV (AD), an autosomal dominant disorder

292 with variable expressivity. Among the various clinical symptoms associated with the disease,

293 limb malformations (e.g. hypoplastic limb and limb reduction) have been reported in a subset of

294 patients (Pepin, Murray \& Byers, 2015; Pepin MG et al., 2014). Genetic testing in the extended

295 family revealed that the mutation was present in the father and his brother (paternal uncle), the

296 latter presenting also with various limb deformities and limb reductions. It is worth noting that

297 null COL3A1 mutations (nonsense mutations) are reported to present with reduced penetrance 
298 and with atypical clinical symptoms, most of these confined to vascular and limb anomalies

299 (Pepin MG et al., 2014; Leistritz DF et al., 2011).

300 Cohort 2 - on-going pregnancies

301 In this cohort of on-going pregnancy cases, Fetalis testing was performed as part of prenatal risk 302 assessment, requested by the couples and the attending obstetrician, following genetic 303 counseling.

304 Case 4, involving a primagravida, the reported US abnormalities in the $12^{\text {th }}$ week of pregnancy

305 were elevated nuchal translucency $(\mathrm{NT}=4.8 \mathrm{~mm})$ and cystic hygroma. Initial prenatal aCGH 306 testing was negative, while subsequent Fetalis testing revealed the heterozygous presence of a 307 known pathogenic PTPN11 mutation c.181G>A (p.Asp61Asn) (rs397507510, Tartaglia M et al., 308 2002) not present in either parent (de novo). Mutations in the PTPN11 gene are associated with 309 the autosomal dominant genetic disorder Noonan syndrome 1 (OMIM 163950), typically 310 presenting with elevated NT and/or cystic hygroma in the $1^{\text {st }}$ trimester ultrasound. The couple 311 decided to terminate the pregnancy and the findings from a subsequent post-mortem histological 312 analysis confirmed the presence of the disease in the male fetus.

313 Case 5, a G2P0 woman, was referred with fetal MRI abnormalities (Dandy-Walker 314 malformation, ventricular dilatation) also observed in the previous pregnancy (terminated).

315 Fetalis testing revealed that the female fetus was compound heterozygous for the ASS1 gene 316 variants/mutations: c.725C $>$ T (p.Thr242Ile) - maternal and c.971G $>$ T (p.Gly324Val) - paternal, 317 the latter being a known pathogenic ASS1 gene mutation (Engel et al., 2009). The maternal 318 c.725C $>$ T (p.Thr242Ile) variant/mutation is not previously reported in any public databases or in 319 the literature and was characterized as probably pathogenic (75\% EMA score). 
320 Mutations in the ASS1 gene are associated with autosomal recessive citrullinemia (OMIM

321 215700), which often presents with congenital brain abnormalities detectable by MRI (Majoie et

322 al., 2004). Following genetic counseling, the couple decided to terminate the pregnancy.

323 Case 6 involved a fetus with ventricular septal heart defect as the sole US finding and aCGH

324 testing (mainly for exclusion of DiGeorge syndrome) was negative. The couple and their

325 obstetrician requested further testing through Fetalis, where it was found that the fetus harbored

326 a heterozygous $P R O K R 2$ c.518T $>$ G (p. L173R) known pathogenic mutation, previously reported

327 in several Kallmann syndrome patients (Sarfati et al., 2010; Sarfati et al., 2013), frequently

328 presenting with septal heart defects. The mother received detailed counseling regarding this

329 finding (father unavailable) and decided to continue with the pregnancy. The requested follow-

330 up information regarding the newborn reported routine surgical correction of the heart defect and

331 at the age of 5 months there are as yet no other phenotypic abnormalities.

332 Case 7 represented a fetus from a G2P0 woman, with reported US and brain MRI abnormalities

333 of rotation of the cerebellar vermis and enlargement of the cisterna magna. The fetus from the

334 previous pregnancy was also reported with identical findings. The Fetalis test revealed the

335 presence of a heterozygous missense mutation c.1208C $>$ A (p.S403Y) of the ZIC1 gene, a gene

336 possibly associated with Dandy-Walker malformation (OMIM 220200). Subsequent

337 confirmatory Sanger sequencing revealed that the mutation was also present in the mother and

338 the variant was reported as a VOUS; however, the family decided to terminate the pregnancy. A

339 post-mortem examination of the fetus was not performed.

340 Finally, in the seven remaining on-going pregnancy cases (Table 1, Case 8 - Case14), Fetalis

341 testing, requested as part of risk assessment for various fetal US abnormalities, did not reveal the

342 presence of variants/mutations which, according to the test criteria (see Materials and Methods), 
343 could be characterized as disease-causing. For all these pregnancies, following post-test genetic

344 counseling, the couples decided to continue the pregnancy, resulting in the birth of seven

345 apparently healthy newborns, presently at the age of 3-5 months old.

347 DISCUSSION

348 The identification of the underlying genetic cause in fetuses with US abnormalities, especially in 349 non-consanguineous families, is a challenging task and prenatal genetic diagnosis is typically

350 limited to the investigation of possible chromosomal imbalances, either through conventional 351 fetal karyotype analysis or, more recently, through aCGH. However, as aCGH will only uncover

352 the underlying genetic cause in $<15 \%$ of these cases (Konialis \& Pangalos, 2015, Hillman et al., 353 2013), an accurate diagnosis is rarely achieved and the necessary advice regarding the precise 354 risks associated with the current pregnancy as well as recurrence risk in subsequent pregnancies 355 is elusive and relies on empirical knowledge. Therefore, the decision to terminate the pregnancy 356 is based solely on the type of fetal ultrasound findings and how the associated risks for a possible 357 severe disorder are perceived by the couple.

In this report we describe the first application of Fetalis, a targeted 758 genes exome sequencing approach, in 3 products of abortion (Cohort 1) and prospectively in 11 on-going pregnancies

361 (Cohort 2), all with diverse abnormal ultrasound findings and of a troubling but non-extreme

362 type, often encountered in routine prenatal diagnosis. Notwithstanding known and unavoidable 363 technical limitations inherent to NGS testing (e.g. incomplete coverage), a highly-likely or 364 definitive diagnosis was achieved in all 3 abortuses and in 3 out of 11 on-going pregnancies, 365 resulting in an overall diagnosis rate of $\sim 36-43 \%$. Although this figure is obviously a very 
366 preliminary assessment from a limited number of cases, it nonetheless provides an initial proof-

367 of-principle regarding the merits of the approach described herein. Most importantly, follow-up

368 data of apparently healthy newborns, born out of on-going pregnancy cases where Fetalis was

369 performed as part of prenatal risk assessment, confirmed the high degree of reassurance provided

370 from the negative results of the test.

371 There are several important issues we wish to address and discuss, regarding the possible clinical

372 use of the Fetalis testing strategy, as described in this report. Although there is no doubt that

373 WES in fetuses with ultrasound abnormalities is in principle expected to provide a considerable

374 increase in our current prenatal diagnostic capabilities, albeit with many caveats (Chitty,

375 Friedman \& Langlois, 2016), the limited data from the few recent studies (Carss et al., 2014;

376 Drury at al., 2015; Alamillo et al., 2015; Westerfield et al., 2015) and from our own initial efforts

377 provide valuable insights to several important limitations regarding its clinical utility in a

378 prenatal setting. Firstly, interpretation of the results following wide scale WES or WGS testing is

379 hampered by the sheer complexity of data analysis and the concomitant difficulties and time

380 required for variant prioritization and final clinical evaluation. Secondly, analysis of WES data

381 will inevitably lead to the uncovering of a large number of incidental findings, unrelated to the

382 reported US findings, leading to serious counseling and ethical issues. The third and most

383 important point is related to the clinical evaluation of numerous WES variants of unknown

384 significance, a very common occurrence in these types of studies.

386 The targeted exome testing strategy described in this report overcomes many of these limitations 387 and concerns. The volume of data (variants) derived from the 758 genes is an order of magnitude 388 less than the corresponding WES data and this fact, coupled to the rapid laboratory protocol and 
389 the custom-developed EMA-Fetalis prioritization pipeline, affords a highly cost-effective, more

390 simplified and timely diagnosis (even $<1$ week) during the course of pregnancy. In addition, the

391 decision to clinically evaluate and report in an on-going pregnancy only known pathogenic

392 variants or 'obligatory' pathogenic variants (see Materials and Methods) reduces dramatically the

393 number of incidental findings (see Results) and the reporting of dubious variants of unknown

394 significance (VOUS), thus simplifying both pre- and post-test genetic counseling. All the above

395 become even more important, if not paramount, when investigating fetuses with less severe US

396 abnormalities, a common troubling occurrence and request in prenatal diagnosis. Although one

397 may argue that the primary purpose and value of prenatal exome sequencing lies in the

398 investigation of highly pathological US anomalies (Filges \& Friedman, 2015), in everyday

399 clinical practice this is not common as both the obstetrician and the parents wish to ascertain

400 whether a less severe US finding (e.g. ambiguous genitalia) may only be 'the tip of the iceberg',

401 hiding underneath other much more serious phenotypic features, not yet apparent through US

402 examination of the developing fetus. In such a case, through precise knowledge of the diseases

403 excluded following our targeted testing approach, a negative test result provides a highly

404 desirable reassurance.

405 To further illustrate the aforementioned points, one could perhaps compare our approach to the

406 application of a targeted $\mathrm{aCGH}$, as opposed to a high-resolution $\mathrm{aCGH}$, in prenatal diagnosis

407 (Konialis \& Pangalos, 2015; Ahn et al., 2014; Oneda et al., 2014; Ganesamoorthy et al., 2013).

408 The Fetalis targeted exome sequencing strategy could be viewed as a targeted aCGH, focusing

409 on regions of known pathogenicity, similar to the implementation of 'focused' lower resolution

410 prenatal aCGH (Ahn et al., 2014). Although it may miss certain abnormalities, possibly picked-

411 up by a more in-depth WES analysis, it has the advantage of avoiding: (a) VOUS, (b) extensive 
412 family studies or costly WES-trio analysis, (c) complicated genetic counseling and perhaps these

413 drawbacks cannot be offset by the possibly higher detection rate.

414 Finally, the Fetalis testing strategy is flexible and its diagnostic yield will definitely increase,

415 without compromising clarity. Although the Fetalis pipeline is currently targeting and evaluating

416 variants detected only in the 758 genes, the initial step in the analysis involves construction of a

417 whole exome (WES) library and therefore whole-exome variant data are readily available.

418 Hence, as we gain more detailed knowledge, the pipeline may continuously incorporate new

419 genes and pathogenic variants, identified through postnatal WES investigations in severely

420 affected newborns and children.

421

422 CONCLUSIONS

423 There is little doubt that prenatal exome sequencing has the potential of becoming soon a routine

424 diagnostic tool. However, as it is applied in a very sensitive and vulnerable setting, we should 425 take the necessary care and precautions so that we do not extend its limits to the point where it

426 might become more of a problem and less relevant and focused to the questions it was set out to

427 resolve.

428

429 To our knowledge, this is the first report exploiting the diagnostic potential of a novel targeted 430 and well defined exome sequencing strategy, which may be deployed rapidly in a clinical

431 prenatal setting and particularly in the course of pregnancy, with minimal ambiguous results and 432 incidental findings. Although the number of cases presented in this report is too small to afford 433 an accurate figure relating to the diagnostic yield, to this end we have initiated an extensive 434 collaborative study with the aim of resolving questions relating to the diagnostic potential of our 
435 approach across different categories of US abnormalities, such as heart malformations, skeletal

436 dysplasias, etc. We believe that the overall Fetalis strategy and the initial data presented in this

437 report provide a sound, affordable and encouraging basis for routine clinical implementation.

438

439 NOTE ADDED IN PROOF: Since the submission of the manuscript, new developments have

440 emerged regarding Case 7 (see Results and Table 1). The couple and their attending obstetrician

441 informed us recently that a new (third) pregnancy is currently at the $23^{\text {rd }}$ week of gestation, with

442 identical fetal ultrasound brain MRI anomalies as the previous two pregnancies and requested

443 clinical genetic evaluation. Suspecting a possible involvement of the maternal ZIClgene variant,

444 we suggested an immediate brain MRI examination of the mother, where it was revealed that she

445 presents with the same structural brain malformations detected in all three fetuses. We

446 subsequently performed a first clinical genetic evaluation of the mother, where a mild Crouzon

447 syndrome-like phenotype was noted, with mild dysmorphic features and irregular head shape. At

448 the time of the initial Fetalis results assessment of Case 7 in May 2015, there had been no

449 published reports directly linking ZIC1 gene variants to a recognizable pathological phenotype

450 and thus, in accordance with our testing and reporting guidelines, the maternally inherited ZIC1

451 gene variant was reported as a VOUS. However, a recent publication (Twigg et al., 2015) has

452 now established an association between ZIC1 gene mutations and coronal craniosynostosis

453 accompanied with structural brain malformations, very similar to those observed in all three

454 fetuses and the mother of Case 7. Further to this recent report, a more detailed clinical evaluation

455 of the mother and of the current pregnancy is under way. We believe that this recent

456 development provides further supporting evidence regarding the specificity and clinical validity

457 of our approach described herein. 


\section{ACKNOWLEDGEMENTS}

The authors wish to thank our colleagues Sophia Karapanou, Sophia Sevastidou and Katerina Pispili for their technical assistance and contributions to this work.

\section{REFERENCES}

Ahn JW, Bint S, Irving MD, Kyle PM, Akolekar R, Mohammed SN, Mackie Ogilvie C. 2014. A new direction for prenatal chromosome microarray testing: software-targeting for detection of clinically significant chromosome imbalance without equivocal findings. Peer J Apr 22;2:e354.

Alamillo CL, Powis Z, Farwell K, Shahmirzadi L, Weltmer EC, Turocy J, Lowe T, Kobelka C, Chen E, Basel D, Ashkinadze E, D'Augelli L, Chao E, Tang S. 2015. Exome sequencing positively identified relevant alterations in more than half of cases with an indication of prenatal ultrasound anomalies. Prenat Diagn 35:1073.

Bell CJ, Dinwiddie DL, Miller NA, Hateley SL, Ganusova EE, Mudge J, Langley RJ, Zhang L, Lee CC, Schilkey FD, Sheth V, Woodward JE, Peckham HE, Schroth GP, Kim RW, Kingsmore SF. 2011. Carrier Testing for Severe Childhood Recessive Diseases by Next-Generation Sequencing. Sci Transl Med 3:65ra4.

Borrelli AL, Arduini D, Cardone A, Ventruto V. 2008. Medicina dell'étà prenatale. SpringerVerlag Mailand. 
Carss KJ, Hillman SC, Parthiban V, McMullan DJ, Maher ER, Kilby MD, Hurles ME. 2014. Exome sequencing improves genetic diagnosis of structural fetal abnormalities revealed by ultrasound. Hum Mol Genet. 23:3269.

Centers for Disease Control and Prevention (CDC) 2008.Update on overall prevalence of major birth defects - Atlanta, Georgia 1978-2005. MMWR Morb Mortal Wkly Rep. $\quad$ 57:1.

Chitty LS, Friedman JM, Langlois S. 2016. Current controversies in prenatal diagnosis 2: should a fetal exome be used in the assessment of a dysmorphic or malformed fetus? Prenat Diagn 36:15.

D'Asdia MC, Torrente I, Consoli F, Ferese R, Magliozzi M, Bernardini L, Guida V, Digilio MC, Marino B, Dallapiccola B, De Luca A. 2013. Novel and recurrent EVC and EVC2 mutations in Ellis-van Creveld syndrome and Weyers acrofacial dyostosis. Eur JMed Genet 56:80.

Drury S, Williams H, Trump N, Boustred C; GOSGene, Lench N, Scott RH, Chitty LS. 2015. Exome sequencing for prenatal diagnosis of fetuses with sonographic abnormalities. Prenat Diagn 35:1010.

Engel K, Höhne W, Häberle J. 2009. Mutations and polymorphisms in the human argininosuccinate synthetase (ASS1) gene. Hum Mutat 30:300.

Ermito S, Dinatale A, Carrara S, Cavaliere A, Imbruglia L, Recupero S. 2009. Prenatal diagnosis of limb abnormalities: role of fetal ultrasonography. J Prenat Med 3:18.

Filges I, Friedman JM. 2015. Exome sequencing for gene discovery in lethal fetal disordersharnessing the value of extreme phenotypes. Prenat Diagn 35:1005.

Ganesamoorthy D, Bruno DL, McGillivray G, Norris F, White, SM, Adroub S, Amor DJ, Yeung A, Oertel R, Pertile MD, Ngo C, Arvaj AR, Walker S, Charan P, Palma-Dias 
R, Woodrow N, Slater HR. 2013. Meeting the challenge of interpreting highresolution single nucleotide polymorphism array data in prenatal diagnosis: does increased diagnostic power outweigh the dilemma of rare variants? BJOG 120:594. GeneTests: Medical Genetics Information Resource (database online). University of Washington, Seattle, 1993-2010, http://www.genetests.org .

Hillman SC, McMullan DJ, HallG, Togneri FS, JamesN, Maher EJ, Meller CH, Williams D, Wapner RJ, Maher ER, Kilby MD. 2013. Use of prenatal chromosomal microarray: prospective cohort study and systematic review and meta-analysis. Ultrasound Obstet Gynecol 41: 610.

Kalynchuk EJ, Althouse A, Parker LS, Saller DN Jr, Rajkovic A. 2015. Prenatal whole- exome sequencing: parental attitudes. Prenat Diagn 35:1030.

Köhler S, Schulz MH, Krawitz P, Bauer S, Dölken S, Ott CE, Mundlos C, Horn D, Mundlos S, Robinson PN. 2009. Clinical diagnostics in human genetics with semantic similarity searches in ontologies. Am J Hum Genet 85:457.

Köhler S, Doelken SC, Mungall CJ, Bauer S, Firth HV, Bailleul-Forestier I, Black GC, Brown DL, Brudno M, Campbell J, FitzPatrick DR, Eppig JT, Jackson AP, Freson K, Girdea M, Helbig I, Hurst JA, Jähn J, Jackson LG, Kelly AM, Ledbetter DH, Mansour $\quad$ S, Martin CL, Moss C, Mumford A, Ouwehand WH, Park SM, Riggs ER, Scott RH, Sisodiya S, Van Vooren S, Wapner RJ, Wilkie AO, Wright CF, Vulto-van Silfhout AT, de Leeuw N, de Vries BB, Washingthon NL, Smith CL, Westerfield M, Schofield $\quad$ P, Ruef BJ, Gkoutos GV, Haendel M, Smedley D, Lewis SE, Robinson PN. 2014. The Human Phenotype Ontology project: linking molecular biology and disease through phenotype data. Nucleic Acids Res 42(Database issue):D966. 
Konialis C, Pangalos C. 2015. Dilemmas in prenatal chromosomal diagnosis revealed through a single center's 30 years' experience and 90,000 cases. Fetal Diagn Ther $38: 218$

Lammens M, Moerman P, Fryns JP, Lemmens F, van de Kamp GM, Goemans N, Dom R. 1997. Fetal akinesia sequence caused by nemaline myopathy. Neuropediatrics 28:116.

Leistritz DF, Pepin MG, Schwarze U, Byers PH. 2011. COL3A1 haploinsufficiency results in a variety of Ehlers-Danlos syndrome type IV with delayed onset of complications and longer life expectancy. Genet Med 13:717.

Long G, Sprigg A. 1998. A comparative study of routine versus selective fetal anomaly ultrasound scanning. J Med Screen 5:6.

Majoie CB, Mourmans JM, Akkerman EM, Duran M, Poll-The BT. 2004. Neonatal citrullinemia: comparison of conventional MR, diffusion-weighted, and diffusion tensor findings. AJNR Am J Neuroradiol. 25:32.

Mankin HJ, Jupiter J, Trahan CA. 2011. Hand and foot abnormalities associated with genetic diseases. Hand (NY) 6:18.

Milunsky A, Milunsky JM. 2015. Genetic Disorders and the Fetus: Diagnosis, Prevention, and Treatment. Wiley-Blackwell.

OMIM Online Mendelian Inheritance in Man., McKusick-Nathans Institute of Genetic Medicine, Johns Hopkins University (Baltimore, MD), 2016. World Wide Web URL: http://omim.org/.

Oneda B, Baldinger R, Reissmann R, Reshetnikova I, Krejci P, Masood,R, Ochsenbein- Kölble N, Bartholdi D, Steindl K, Morotti D, Faranda M, Baumer A, Asadollahi R, $\quad$ Joset P, Niedrist D, Breymann C, Hebisch G, Hüsler M, Mueller R, Prent E, Wisser J, Zimmermann 
R, Rauch A. 2014. High resolution chromosomal microarrays in prenatal diagnosis significantly increase diagnostic power. Prenat Diagn 34:525.

Pepin MG, Schwarze U, Rice KM, Liu M, Leistritz D, Byers PH. 2014. Survival is affected by mutation type and molecular mechanism in vascular Ehlers-Danlos syndrome (EDS type IV). Genet Med 16: 881 .

Pepin MG, Murray ML, Byers, PH. (Last Update: November 19, 2015). Vascular Ehlers- Danlos Syndrome. In: GeneReviews at GeneTests Medical Genetics Information Resource (database online).

Porter FD, Herman GE. 2011. Malformation syndromes caused by disorders of cholesterol synthesis. J Lipid Res 52:6.

Rice KJ, Ballas J, Lai E, Hartney C, Jones MC, Pretorius DH. 2011. Diagnosis of fetal limb abnormalities before 15 weeks: cause for concern. J Ultrasound Med 30:1009.

Richards S, Aziz N, Bale S, Bick D, Das S, Gastier-Foster J, Grody WW, Hegde M, Lyon E, Spector E, Voelkerding K, Rehm HL; ACMG Laboratory Quality Assurance Committee. 2015. Standards and guidelines for the interpretation of sequence variants: a joint consensus recommendation of the American College of Medical Genetics and Genomics and the Association for Molecular Pathology. Genet Med 17:405.

Romosan G, Henriksson E, Rylander A, Valentin L. 2009. Diagnostic performance of routine ultrasound screening forfetal abnormalities in an unselected Swedish population in 2000-2005. Ultrasound Obstet Gynecol 34: 526.

Ryan MM, Schnell C, Strickland CD, Shield LK, Morgan G, Iannaccone ST, Laing NG, Beggs AH, North KN. 2001. Nemaline myopathy: a clinical study of 143 cases. Ann Neurol $50: 312$. 
Sabbagha R, Tamura R, Sabbagha E. 2015. Ultrasound Diagnosis of Fetal Anomalies. In: Glob. libr. women's med., DOI 10.3843/ GLOWM.10205.

Sarfati J, Guiochon-Mantel A, Rondard P, Arnulf I, Garcia-Piñero A, Wolczynski S, BraillyTabard S, Bidet M, Ramos-Arroyo M, Mathieu M, Lienhardt-Roussie A, Morgan G, Turki Z, Bremont C, Lespinasse J, Du Boullay H, Chabbert-Buffet N, Jacquemont S, Reach G, De Talence N, Tonella P, Conrad B, Despert F, Delobel B, Brue T, Bouvattier C, Cabrol S, Pugeat M, Murat A, Bouchard P, Hardelin JP, Dodé C, Young J. 2010. A comparative phenotypic study of kallmann syndrome patients carrying monoallelic and biallelic mutations in the prokineticin 2 or prokineticin receptor 2 genes. J Clin Endocrinol Metab 95:659.

Sarfati J, Fouveaut C, Leroy C, Jeanpierre M, Hardelin JP, Dodé C. 2013. Greater prevalence of PROKR2 mutations in Kallmann syndrome patients from the Maghreb than in European patients. Eur J Endocrinol 169:805.

Saunders CJ, Miller NA, Soden SE, Dinwiddie DL, Noll A, Alnadi NA, Andraws N, Patterson ML, Krivohlavek LA, Fellis J, Humphray S, Saffrey P, Kingsbury Z, Weir JC, Betley J, Grocock RJ, Margulies EH, Farrow EG, Artman M, Safina NP, Petrikin JE, Hall KP, Kingsmore SF. 2012. Rapid whole-genome sequencing for genetic disease diagnosis in neonatal intensive care units. Sci Transl Med. 4:154ra135.

Schramm T, Gloning KP, Minderer S, Daumer-Haas C, Hörtnagel K, Nerlich A, Tutschek B. 2009. Prenatal sonographic diagnosis of skeletal dysplasias. Ultrasound Obstet Gynecol 34: 160. 
Shen W, Han D, Zhang J, Zhao H, Feng H. 2011. Two novel heterozygous mutations of EVC2 cause a mild phenotype of Ellis-van Creveld syndrome in a Chinese family. $\quad$ Am J Med Genet Part A 155:2131.

Stenson PD, Mort M, Ball EV, Howells K, Phillips AD, Thomas NS, Cooper DN. 2009. The Human Gene Mutation Database: 2008 update. Genome Med. 1:13.

Talkowski ME, Ordulu Z, Pillalamarri V, Benson CB, Blumenthal I, Connolly S, Hanscom C, Hussain N, Pereira S, Picker J, Rosenfeld JA, Shaffer LG, Wilkins-Haug LE, Gusella JF, Morton CC. 2012. Clinical diagnosis by whole-genome sequencing of a prenatal sample. N Engl J Med 367:2226.

Tartaglia M, Kalidas K, Shaw A, Song X, Musat DL, van der Burgt I, Brunner HG, Bertola DR, Crosby A, Ion A, Kucherlapati RS, Jeffery S, Patton MA, Gelb BD. 2002. PTPN11 mutations in Noonan syndrome: molecular spectrum, genotype-phenotype correlation, and phenotypic heterogeneity. Am J Hum Genet 70:1555.

Twigg SR, Forecki J, Goos JA, Richardson IC, Hoogeboom AJ, van den Ouweland AM, Swagemakers SM, Lequin MH, Van Antwerp D, McGowan SJ, Westbury I, Miller KA, Wall SA, WGS500 Consortium, van der Spek PJ, Mathijssen IM, Pauws E, Merzdorf CS, Wilkie AO. 2015. Gain-of-Function Mutations in ZIC1 Are Associated with Coronal Craniosynostosis and Learning Disability. Am J Hum Genet. 97:378.

Warman ML, Cormier-Daire V, Hall C, Krakow D, Lachman R, LeMerrer M, Mortier G, Mundlos S, Nishimura G, Rimoin DL, Robertson S, Savarirayan R, Sillence D, Spranger J, Unger S, Zabel B, Superti-Furga A. 2011. Nosology and classification of genetic skeletal disorders: 2010 revision. Am J Med Genet A 155A:943.

Westerfield LE, Stover SR, Mathur VS, Nassef SA, Carter TG, Yang Y, Eng CM, Van 
den Veyver IB. 2015. Reproductive genetic counseling challenges associated with diagnostic exome sequencing in a large academic private reproductive genetic counseling practice. Prenat Diagn 35:1022. 
Table 1: Reported fetal ultrasound findings, Fetalis exome sequencing results, disease diagnosis and pregnancy outcome

\begin{tabular}{|c|c|c|c|c|c|c|}
\hline Case $^{\mathbf{a}}$ & $\begin{array}{l}\text { Gestation } \\
\text { week }\end{array}$ & U/S findings & Prior history* & Gene variants detected & Diagnosis - syndrome & $\begin{array}{r}\text { Confirmation and/or pregnancy } \\
\text { outcome }\end{array}$ \\
\hline 1 & $\begin{array}{l}\text { Abortus, } \\
27 \mathrm{wk}\end{array}$ & Multiple limb deformities & No & $\begin{array}{l}E V C 2 \text { c.2776G }>\text { A (p.E926K) \& c.707T }>C \\
\text { (p.V236A), double heterozygous }\end{array}$ & Ellis-van Creveld syndrome (AR) & Parents carriers \\
\hline 2 & $\begin{array}{l}\text { Abortus, } \\
22 \mathrm{wk}\end{array}$ & $\begin{array}{l}\text { IUGR, joint contractures, mild } \\
\text { hydrocephalus, decreased fetal } \\
\text { movements }\end{array}$ & Yes & $\begin{array}{c}N E B \text { c. } 11060 \mathrm{C}>\mathrm{T} \text { (p.A3687V) \& c. } 11333 \mathrm{~T}>\mathrm{C} \\
\text { (p.I3778T), double heterozygous }\end{array}$ & Nemaline myopathy (AR) & $\begin{array}{l}\text { Parents carriers, both mutations present in } \\
\text { previously affected fetus }\end{array}$ \\
\hline 3 & $\begin{array}{l}\text { Abortus, } \\
18 \mathrm{wk}\end{array}$ & $\begin{array}{l}\text { Hypoplastic right antebrachium, } \\
\text { wrist and phalangeal defects of } \\
\text { right hand }\end{array}$ & No & COL3A1 c. $811 \mathrm{C}>\mathrm{T}$ (p.R271X), het & Ehlers-Danlos syndrome IV (AD) & $\begin{array}{l}\text { Paternally inherited, mutation } \\
\text { present in affected uncle }\end{array}$ \\
\hline 4 & $12 w k$ & $\begin{array}{l}\text { NT } 4.8 \mathrm{~mm} \text { and cystic hygroma in } \\
1^{\text {st }} \text { trimester screen }\end{array}$ & No & PTPN11 c.181G $>$ A (p.D61N), heterozygous & Noonan syndrome (AD) & $\begin{array}{l}\text { de novo mutation, known pathogenic, } \\
\text { pregnancy terminated }\end{array}$ \\
\hline 5 & $23 \mathrm{wk}$ & Brain MRI abnormalities & Yes & $\begin{array}{l}\text { ASS1 c. } 725 \mathrm{C}>\mathrm{T} \text { (p.T242I) \& c.971G }>\mathrm{T} \\
\quad \text { (p.G324V), double heterozygous }\end{array}$ & Citrullinemia (AR) & $\begin{array}{c}\text { Parents carriers, } \\
\text { pregnancy terminated, } \\
\text { similar findings in previous pregnancy }\end{array}$ \\
\hline 6 & $22 \mathrm{wk}$ & $\begin{array}{l}\text { Interventricular septum heart } \\
\text { defect }\end{array}$ & No & PROKR2 c.518T >G (p. L173R), heterozygous $\S$ & $\begin{array}{l}\text { PROKR2-related Kallmann } \\
\text { syndrome (AD) }\end{array}$ & $\begin{array}{l}\text { Live birth, } 5 \mathrm{mo} \text {, surgical correction of hear } \\
\text { defect, no other abnormality }\end{array}$ \\
\hline 7 & $27 w k$ & $\begin{array}{l}\text { Rotation of the cerebellar vermis, } \\
\text { enlargement of the cisterna magna }\end{array}$ & Yes & ZIC1 c.1208C >A (p.S403Y), heterozygous & $\begin{array}{l}\text { Association with Dandy-Walker } \\
\text { malformation, VOUS }\end{array}$ & $\begin{array}{l}\text { Maternally inherited, previous pregnancy } \\
\text { terminated with identical findings, } \\
\text { pregnancy subsequently terminated }\end{array}$ \\
\hline 8 & $22 \mathrm{wk}$ & $\begin{array}{l}\text { IUGR, short nasal bone, short } \\
\text { long bones, possible hypospadias }\end{array}$ & No & No pathogenic mutation & - & Live birth, $9 \mathrm{mo}$, no abnormality reported \\
\hline 9 & $22 w k$ & Unilateral clinodactyly & No & No pathogenic mutation & - & Live birth, $6 \mathrm{mo}$, no abnormality reported \\
\hline 10 & $18 \mathrm{wk}$ & Right hand polydactyly & No & No pathogenic mutation & - & $\begin{array}{l}\text { Live birth, } 5 \text { mo, slight deformity- } \\
\text { pseudodactyly surgically corrected, no othe } \\
\text { abnormality }\end{array}$ \\
\hline 11 & $21 \mathrm{wk}$ & $\begin{array}{l}\text { Hydronephrosis, echogenic bowel, } \\
\text { brachymelia }\end{array}$ & No & No pathogenic mutation & - & Live birth, $5 \mathrm{mo}$, no abnormality reported \\
\hline 12 & $24 w k \pi$ & Hydronephrosis & No & No pathogenic mutation & - & Live birth, 4 mo, no abnormality reported \\
\hline 13 & $24 w k \pi$ & $\begin{array}{l}\text { Short humerus and femur, } \\
\text { echogenic bowel }\end{array}$ & No & No pathogenic mutation & - & Live birth, 4 mo, no abnormality reported \\
\hline
\end{tabular}


${ }^{a}$ Cohort 1 - abortuses: cases 1-3. Cohort 2 - on-going pregnancies: cases 4-14.

* Prior pregnancies with similar ultrasound findings. ${ }^{\uparrow}$ Twin pregnancy. ${ }^{\S}$ Parents as yet unavailable for testing. 